\title{
Диффузия атомов 1, 2 и 13-й групп на поверхности топологических изоляторов
}

\author{
Рябищенкова А.Г.
}

Томский государственный университет, 634050, Томск, пр. Ленина, 36

DOI 10.34077/Semicond2019-500

Исследование топологических изоляторов (ТИ) является актуальной задачей современной физики твердого тела. Эти материалы обладают экзотическими свойствами - являются изоляторами в объеме и имеют топологически защищенные проводящие состояния на поверхности [1]. Электроны, находящиеся в таких состояниях, защищены симметрией относительно обращения времени от упругого обратного рассеяния на дефектах, что способствует протеканию электрического тока почти без потерь энергии. Благодаря этому ТИ имеют огромный потенциал для спинтроники и спинтронных устройств. Адсорбция различных атомов на поверхность ТИ позволяет управлять различными их свойствами, при этом, сохраняя топологическое состояние на поверхности. Так, например, адсорбция атомов 1 группы позволяет управлять свойствами фермионов Дирака на контакте немагнитных атомов и ТИ $\mathrm{Sb}_{2} \mathrm{Te}_{3}$ [2]. Тогда как интеркаляция атомов 2 и 13 групп в топологический изолятор $\mathrm{Bi}_{2} \mathrm{Se}_{3}$ приводит к возникновению сверхпроводимости $[3,4]$. Интеркаляция - это внедрение примесных атомов в межблочные промежутки, которые называются ван дер Ваальсовыми промежутками слоистых систем. Существует ещё несколько работ, в которых делаются предположения для химически похожих атомов о том, что в одном случае происходит десорбция, а в другом - инеркаляция [5,6]. Таким образом, вопрос о локализации атомов, их возможных путях диффузии на поверхности, а также энергиях активации на настоящий момент является актуальным.

В работе представлены результаты первопринципных расчетов адсорбции и диффузии адатомов 1, 2 и 13 групп на (0001) поверхностях топологических изоляторов на основе халькогенидов. На основе первопринципных расчетов энергий адсорбции было определено равновесное положение адатомов $1(\mathrm{Li}, \mathrm{Na}, \mathrm{K}, \mathrm{Rb}, \mathrm{Cs}), 2$ (Be, $\mathrm{Mg}, \mathrm{Ca}, \mathrm{Sr}$ и $\mathrm{Ba}$ ) и 13 (B, Al, $\mathrm{Ga}, \mathrm{In}$ и Tl) групп на поверхности (0001) тетрадимитоподобных ТИ. Для выявленного равновесного положения было определено зарядовое состояние каждого из адатомов, охарактеризован тип его связи с поверхностью, а также рассчитана равновесная высота его адсорбции над поверхностью и длина связи адатома с ближайшим атомом поверхностного слоя. В рамках метода упругой ленты были рассчитаны энергии активации диффузии и оценены диффузионные длины адатомов 2 и 13 групп на бездефектной поверхности (0001) тетрадимитоподобных ТИ. Исследована возможность интеркаляции отдельных адатомов, при условии выгодности позиции под поверхностью, со ступенчатой поверхности (0001) ТИ в его приповерхностные ван-дер-Ваальсовы пустоты.

Исследование выполнено при финансовой поддержке РФФИ в рамках научного проекта № 1832-01068 мол_а.

[1] M. Hasan and C. Kane, Rev. Mod. Phys., 82, 3045 (2010).

[2] C. Seibel, H. Maab, M. Ohtaka et al., Phys. Rev. B, 86, 235105(2012).

[3] V. K. Shruti, P. Maurya, P. Neha et. al., Phys. Rev. B, 92, 020506 (2015).

[4] L. Wu, M. Brahlek, R. V. Aguilar et. al., Nature Physics, 9, 410 (2013).

[5] M. Bianchi, R. C. Hatch, Z. Li et. al., ACS Nano, 6, 7009 (2012).

[6] Z.-H. Zhu, G. Levy, B. Ludbrook, et. al., Phys. Rev. Lett., 107, 186405(2011). 